\title{
miscellany
}

\section{Florence Nightingale Hospitals confronts growing problem of teenage mental illness}

In $199920 \%$ of suicidal callers to the mental health helpline SANELINE were aged 15-24 years; teenage mental illness is on the increase in our society. Statistics show that throughout the past decade there have been approximately 19000 suicide attempts by adolescents every year and at least two teenagers a day actually succeed in killing themselves. Although media attention has heightened awareness of the problem, very little has changed in the way these young people are treated. There is a distinct lack of available facilities for the specialist treatment of adolescent mental illness. Florence Nightingale Hospitals aims to help redress the situation, with the opening of its Young Persons Centre. Here, adolescents can benefit from focused specialist care, including an adapted educational programme and group therapy sessions. Emphasis is placed on helping the teenagers and their families understand their illness and teaching them how to cope with it in its early stages, and perhaps avoid getting caught in the 'revolving hospital door'. The Central London unit offers treatment by a multi-disciplinary team consisting of consultant psychiatrists, a clinical psychologist, family counsellor, art psychotherapist, social worker, teacher and senior nurse manager and nursing staff.

For further details contact Zsara Hodgkinson, Marketing Manager, Florence Nightingale Hospitals; tel: 020 7535 7746; e-mail: Zsara.hodgkinson @ cmel.bure.se, or Anna Wright, SPARX Communications; tel: 01753893 000; e-mail: anna@sparx.uk.com.

\section{Lilly Schizophrenia Reintegration Awards}

The Westbury Mental Health Initiative was announced as the winner of the 2000 Lilly Schizophrenia Reintegration Awards. The team, comprising a community psychiatric nurse, general practitioner and practice manager, from the Eastleigh surgery, Westbury in Wiltshire, won the highly acclaimed national award in recognition of the development of a comprehensive mental health initiative to improve standards of care for people with schizophrenia. This included streamlining care for both clients and their relatives and carers, improving communications between secondary and primary care services and managing appropriate use of antipsychotic medication. The annual awards were introduced to recognise and reward outstanding achievement in helping patients with schizophrenia and related disorders overcome barriers in reintegrating into society. The awards are aimed at health care professionals who are based in, or who have strong links with, primary care.

\section{Mind - the Vietnam bike ride}

Leading mental health charity Mind is offering the adventurous an amazing opportunity; the chance to take part in a sponsored bike ride through Vietnam in November 2001. This exciting 10-day trip takes participants from the majestic Marble Mountains to the bustling city of Saigon via an amazing backdrop of verdant rainforest and paddy fields. It also offers the rare opportunity to step back in time away from the pressures of modern life and experience the overwhelming friendliness of the Vietnamese people.

In return for the initial fee of $f 299$ and minimum sponsorship level, entrants will receive all accommodation, meals, bike, lots of moral and fund-raising support. You don't have to be super-fit because Mind will provide training advice to ensure everyone is ready for the challenge. Prizes will also be awarded to top fund-raisers.

Sponsorship from just one participant could fund the entire Mind InfoLine for 4 working days, helping 400 people in crisis. Mind provides vital support to the one in four people experiencing mental health problems.

To find out more about the bike ride call 08700129001 or e-mail vietnam@mind.org.uk.

\section{Certificate in community mental health care}

The certificate offers comprehensive cover of the core knowledge, skills and attitudes needed by practitioners to deliver effective and safe client-centred services across the broad spectrum of mental health services in the UK.

The qualification is aimed at staff, volunteers, service users and carers who do not have a professional qualification relating to mental health and are involved in the delivery of mental health services in some way. Such services may include residential, day care or drop-in services, advocacy, in-patient and out-patient care, supported housing, supported employment, home and general community support and specialist services such as those for homeless people. The certificate may be taken independently or alongside other vocational training. It may also be used as either a stepping stone onto or following professional training.

There are no prerequisite qualifications, learning or experience for students of the certificate, however City \& Guilds Affinity recommends that in order for students to fully benefit from the qualification they should have some current or past practical experience in the mental health field to draw on. They should already have completed their induction period within the workplace or the equivalent.

The assessment strategy for the certificate allows students to gradually build up achievement to the full certificate at their own speed and the Qualifications and Curriculum Authority has formally accredited the certificate, which means that it is part of the National Qualifications Framework for England and Wales. The awarding body for the certificate will be City \& Guilds. For further information visit the website (http://www.mentalhealth.org.uk/certificate).

\section{Innovative new website makes connections for those affected by autism}

From 18 October 2000 searching for information about autism on the internet will be much easier owing to a new sophisticated, yet user-friendly, website entitled 'autismconnect' (http://www. autismconnect.com). The project is a partnership between the National Autistic Society, the Shirley Foundation and the web developer RMR plc.

The website is a free, non-commercial service that aims to be the first port of call for anyone interested in finding up-todate information about autism and related autistic spectrum disorders. This includes people with an autistic disorder, their parents, friends, educators and therapists, as well as researchers, legislators and volunteers.

The site will contain details of other websites, events, conferences, support groups, organisations and the latest research from around the world.

\section{The Morris Markowe Public Education Prize}

The prize was established in 1989 from funds donated in the memory of the late $\mathrm{Dr}$ Morris Markowe, Honorary Fellow and Registrar of the Royal College of Psychiatrists from 1972-1998. An award will be made this year of $£ 400$ to the successful entrant.

\section{Regulations:}

The Morris Markowe Prize is awarded annually for: 